Tropical Journal of Pharmaceutical Research August 2010; 9 (4): 329-337

(C) Pharmacotherapy Group, Faculty of Pharmacy, University of Benin,

Benin City, 300001 Nigeria.

All rights reserved.

Available online at http://www.tjpr.org

Research Article

\title{
Effect of Cream Formulation of Fenugreek Seed Extract on Some Mechanical Parameters of Human Skin
}

\author{
N Akhtar ${ }^{1}$, MK Waqas ${ }^{1}$, M Ahmed $^{1}$, T Saeed ${ }^{2}$, G Murtaza $^{1 *}$, A \\ Rasool $^{1}$, MN Aamir ${ }^{1}$, SA Khan ${ }^{1}$, NS Bhatti ${ }^{3}$ and A Ali ${ }^{3}$ \\ ${ }^{1}$ Department of Pharmacy, Faculty of Pharmacy and Alternative Medicines, The Islamia University of Bahawalpur, \\ Bahawalpur $63100,{ }^{2}$ College of Pharmacy, The University of the Punjab, Lahore, ${ }^{3}$ Department of Pharmacy, the \\ University of Faislabad, Faisalabad, Pakistan.
}

\begin{abstract}
Purpose: To determine the effect of an emulsion formulation of fenugreek (Trigonella Foneum-Graecum $L$ ) seed extract on some mechanical parameters of the skin of healthy human volunteers

Methods: A water-in-oil emulsion cream base without fenugreek seed extract which served as control, and a similar formulation containing $4 \% \mathrm{w} / \mathrm{v}$ of the extract in the internal (aqueous) phase were prepared. Each of the formulations was applied to the cheeks of 10 human volunteers for a period of 4 weeks and some mechanical parameters (R0, R1, R2, R3, R4, R5, R6, R7, R8 and R9) of the skin were measured weekly using Cutometer MPA 580.

Results: The results indicate that the effects of the creams on skin mechanical properties were significant $(p<0.05)$ with respect to time, except for $R 4$ and $R 9$. The extract-containing cream substantially increased skin elasticity, hydration and the ability of skin to resist photo-aging when compared to the base.

Conclusion: Both the cream base and the cream containing fenugreek extract demonstrated significant $(p<0.05)$ improvement in all mechanical parameters related to skin elasticity, ageing, hydration and fatigue but the effect of the extract cream was more pronounced in some cases.
\end{abstract}

Keywords: Cutometer, Fenugreek seed extract, Skin elasticity, Skin ageing, Skin hydration 


\section{INTRODUCTION}

Skin has good frictional properties, assisting locomotion and manipulation due to its texture. It is elastic and can be stretched and compressed within limits [1]. Elastic fibres within the skin form a fibrous network that is interwoven between the collagen bundles throughout the dermis [1]. As aging occurs, human skin gets more wrinkled, become drier and loses its elasticity. Evaluation of skin elasticity is especially important, because it is not as visible as other signs of aging such as wrinkles [2]. Skin mechanical parameters are most sensitive to epidermal hydration. Epidermal hydration produced by moisturizers influences the mechanical properties of skin. Accumulation of water in the dermis diminishes friction between fibres and facilitates movement of the interstitial fluid. At the upper level, they are attributed to the softening of the outer layers of the epidermis (mainly stratum corneum) [3].

Non-invasive skin elasticity measurements are appropriate for an objective and quantitative evaluation of the complex effect of different dermatological and cosmetic products on epidermal mechanics and water content. In skin suction experiments, the skin is elevated into a circular aperture, using low pressure. During the experiment, skin elevation is continuously measured using an optical system in the aperture. These experiments are usually performed in timeelevation mode: the suction is switched on and off a number of times and elevation is measured as a function of time. The different plots so obtained are normally evaluated by partitioning the response near the pressure switching points, into an immediate (elastic) and delayed (non-elastic) portion [4].

Emulsions are defined as a thermodynamically unstable system consisting of at least two immiscible liquid phases, one of which is dispersed as globules (disperse phase) in the other liquid phase (continuous phase), stabilized by the presence of an emulsifying agent [5]. Emulsions offer promising applications in pharmaceutical, food and cosmetic industries. There has been renewed interest in emulsion as a vehicle for delivering drugs to the body as it has been found to have several advantageous characteristics, including enhancing the bioavailability of the drug substance. In an emulsion, therapeutic properties and spreading ability of the constituents are increased [6].

The seeds of fenugreek (Trigonella FoneumGraecum L) are primarily composed of galactomannans. Galactomannan is a natural effective ingredient for improving skin hydration, possibly through a humectant mechanism [7]. An extract of fenugreek can be obtained by macerating the powdered seeds in $80 \%$ methanol, filtering and concentrating it in a rotary evaporator.

The aim of this study was to measure the effect of a W/O cream of fenugreek seed extract on the mechanical parameters of skin such as R0, R1, R2, R3, R4, R5, R6, R7, R8 and $\mathrm{R} 9$.

\section{EXPERIMENTAL}

\section{Materials}

Fenugreek seed was purchased from a local shop in Bahawalpur and authenticated by Prof. Dr. Muhammad Arshad, Head of Cholistan Institute of Desert Plants Studies, the Islamia University of Bahawalpur, Bahawalpur, Pakistan. A voucher specimen (no. 127-Ch/2008) has been kept in the herbarium at Cholistan Institute of Desert Plants Studies, the Islamia University of Bahawalpur, Bahawalpur, Pakistan. Paraffin oil was obtained from Merck, Germany, AbilEM 90 (dimethicone copolyol) from Franken Chemicals, Germany and lemon oil was purchased locally.

The instruments used include Cutometer MPA 580, MPA 5 (Courage + Khazaka, Germany), Digital Humidity Meter (TES Electronic Corp, Taiwan); electrical Balance (Precisa BJ-210, Switzerland); homogenizer 
(Euro-Star, IKA D 230, Germany); pH-Meter (WTW pH-197i, Germany); rotary evaporator (Eyela, Co. Ltd. Japan); and a water bath (HH S214., China).

\section{Preparation of Fenugreek seed extract}

An extract of fenugreek was obtained by macerating the powdered seeds of fenugreek in $80 \%$ methanol. It was then filtered and concentrated to dryness using a rotary evaporator.

\section{Preparation of formulations}

W/O emulsion was prepared by adding the aqueous phase to the oily phase with continuous agitation. The oily phase consisted of paraffin oil (16\%) and surfactant (ABIL- EM 90, $3.5 \%$ ) which were heated to $75 \pm 1{ }^{\circ} \mathrm{C}$. The aqueous phase (distilled water) was heated to the same temperature and the fenugreek seed extract, at a concentration of $4 \% \mathrm{w} / \mathrm{v}$, was added to it. The aqueous phase was added to the oil phase dropwise while stirring at $2000 \mathrm{rpm}$ with a mechanical mixer for $15 \mathrm{~min}$. Lemon oil (2 or 3 drops) was also added while stirring to impart good fragrance to the formulation. Following the addition of the aqueous phase, the speed of the mixer was reduced to 1000 rpm for 5 min to achieve homogenization; the speed of the mixer was further reduced to $500 \mathrm{rpm}$ for $5 \mathrm{~min}$ to attain complete homogenization. The emulsion was cooled to room temperature. The cream base, which served as control, was prepared as described above except that no extract was incorporated

\section{Skin studies}

This study was approved by the Board of Advanced Studies and Research, and its Ethical Committee for In-vivo Studies (ref no. 12-IUB/M.Phil.), The Islamia University of Bahawalpur and was conducted according to the international guidelines of Helsinki Declaration [8]. Ten male volunteers, whose ages ranged from 25 to 45 years, were selected. Prior to the tests, the volunteers were examined by a dermatologist for any serious skin disease or damage, especially on cheeks and forearms. Before the study, every volunteer was provided with the study protocol stating the terms and conditions of the tests and their individual written consent was obtained. The skin tests were carried out at $25{ }^{\circ} \mathrm{C}$ and $40 \%$ relative humidity. On the first day, Burchard patch test was performed on the forearms of each volunteer to determine any possible reactions to the creams. A $5 \mathrm{~cm} \times 4 \mathrm{~cm}$ region was marked on both forearms. Basic values for erythema and melanin were measured with the help of a mexameter. One gram of base and formulation each were applied to the marked regions of the forearm. The regions were covered with surgical dressing after application. After 24 hours, the dressings were removed and the measurements of erythema and melanin were repeated on both forearms. Next day, each volunteer was administered with two creams on the cheeks. One cream was the base and the other one contained the active ingredient. Each cream was marked "right" or "left" indicating application of the cream to the right and left cheek, respectively. The creams (approximately $0.5 \mathrm{~g}$ ) were applied gently by the volunteers themselves once every night before going to bed, as instructed, for 28 days. Every individual was instructed to come on weeks 1, 2, 3, and 4 for skin assessment.

\section{Skin elasticity measurement}

The mechanical properties of the skin were determined with a non-invasive suction skin elasticity meter (Cutometer MPA 580). A 2 $\mathrm{mm}$ diameter measuring probe was used which applied a constant suction of 350 mbar with time/strain mode (Mode 1) for $18 \mathrm{~s}$, followed by a relaxation time of $2 \mathrm{~s}$, with two repetitions. Measurements were made on a single site at face. The Cutometer generates a graph depicting immediate deformation or skin extensibility (Ue), delayed distension (Uv), final deformation (Uf), immediate retraction (Ur), total recovery (Ua) and 
residual deformation at the end of measuring cycle (R) as represented in Figure 1. Parameters of skin deformation curves generated by cutometer were then mathematically and statistically analyzed.

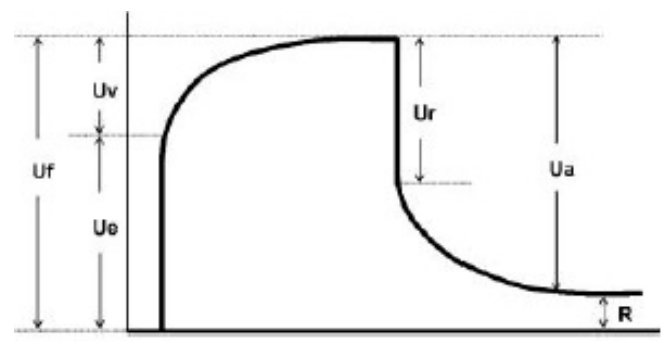

Fig. 1: Typical skin deformation curve obtained by Cutometer

The first part of the curve is considered as the elastic component and is termed Ue while the second part of the curve characterized the viscoelastic part of the skin, mainly the plastic component, and is represented by Uv. The maximum amplitude of the curve Uf consists of: Uf $=\mathrm{Ue}+\mathrm{Uv}$. After the suction phase, the vacuum in the probe is automatically switched to 0 mbar of negative pressure. Here the curve drops, and in viscoelastic materials such as skin, the two parts of the curve can be seen, namely, the perpendicularly dropping elastic component, Ur, and the viscoelastic component which is mathematically equal to $\mathrm{Ua}-\mathrm{Ur}$, where $\mathrm{Ua}$ is the total recovery after the suction phase. The R-parameters given by the Cutometer are: $\mathrm{R} 0=\mathrm{Uf}, \mathrm{R} 1=\mathrm{Uf}-\mathrm{Ua}, \mathrm{R} 2=\mathrm{Ua} / \mathrm{Uf}, \mathrm{R} 3=$ last max. amplitude, $\mathrm{R} 4=$ last min. amplitude, $\mathrm{R} 5=\mathrm{Ur} / \mathrm{Ue}, \mathrm{R} 6=\mathrm{Uv} / \mathrm{Ue}, \mathrm{R} 7=\mathrm{Ur} / \mathrm{Uf}, \mathrm{R} 8$ $=\mathrm{Ua}$ and $\mathrm{R} 9=\mathrm{R} 3-\mathrm{R} 0$.

\section{Mathematical analysis}

The percent weekly changes for the individual values of the parameters for the volunteers were calculated by Eq 1 .

Percent change $=[(A-B) / B]^{\star} 100$

where $\mathbf{A}=$ individual value of any parameter on $1^{\text {st }}, 2^{\text {nd }}, 3^{\text {rd }}$ or $4^{\text {th }}$ week, and $\mathbf{B}=$ zero hour value of the parameter

\section{Statistical analysis}

The measured values obtained for the different parameters (R0, R1, R2, R3, R4, $R 5, R 6, R 7, R 8$ and $R 9$ ) were analyzed using SPSS 15.0 (paired samples t-test for variation between the two preparations, and two-way ANOVA for variation between different time intervals. At $95 \%$ confidence interval, $p$ values $<0.05$ were considered significant.

\section{RESULTS}

The values of various $R$-parameters following the application of the base and formulation on the cheeks of human volunteers are presented in Table 1. It was found that after application of the base cream, there was increase in $R 0$ values in the $2^{\text {nd }}$ and $3^{\text {rd }}$ week but a slight decrease was observed in the $1^{\text {st }}$ and $4^{\text {th }}$ week. On the other hand, following application of extract cream, there was continuous increase in R0 values until the $3^{\text {rd }}$ week but this increase was slightly less in the $4^{\text {th }}$ week of the study. The values of $R 1$ increased throughout the study period after the application of base, showing the highest values in $3^{\text {rd }}$ week, while after application of the extract cream, the opposite effect, i.e. decrease in R1 values, occurred with the lowest value in the $2^{\text {nd }}$ week. The values of R2 decreased markedly in the $1^{\text {st }}$ week of the study, but increased in the $2^{\text {nd }}$ and $4^{\text {th }}$ week after application of the base; following application of the extract cream, there was almost the same level of increase in R2 values throughout the study period.

Following application of the base, increase in R3 values occurred in the $2^{\text {nd }}$ and $3^{\text {rd }}$ week and a slight decrease in the $1^{\text {st }}$ and $4^{\text {th }}$ week, while after application of the extract cream, there was almost no change in R3 values until the $3^{\text {rd }}$ week when it increased; but the increase was slightly less in the $4^{\text {th }}$ week. The values of R4 increased throughout the study period after the application of the base, but this increase continuously diminished as the study progresse; on application of the extract 
cream, decrease in R4 values occurred except in the $3^{\text {rd }}$ week where values increased. Base was application led to a decrease in $\mathrm{R} 5$ values in the $1^{\text {st }}$ and $3^{\text {rd }}$ week but increase in the $2^{\text {nd }}$ and $4^{\text {th }}$ week. On the other hand, on application of the extract cream, there was a tremendous increase in R5 values throughout the study period except in the $3^{\text {rd }}$ week where the increase was small. Following application of the base, decrease in R6 values in the $2^{\text {nd }}$ and $3^{\text {rd }}$ week was observed but values increased in the $1^{\text {st }}$ and $4^{\text {th }}$ week; on application of extract cream, there was a pronounced increase in the values of $R 6$ throughout the study period except in the $3^{\text {rd }}$ week when the values decreased. $\mathrm{R} 7$ values decreased markedly in the $1^{\text {st }}$ week of study on application of the base, but increase was observed in the $2^{\text {nd }}$, $3^{\text {rd }}$ and $4^{\text {th }}$ week.

However, after application of the extract, there was substantial increase in $\mathrm{R} 7$ values throughout the study period. $\mathrm{R} 8$ values decreased in the $1^{\text {st }}$ week after application of the base, but increased in subsequent weeks while there was pronounced increase in $R 8$ values in a regular pattern throughout the study period after application of the cream extract.

The values of $\mathrm{R} 9$ increased throughout the

Table 1: Values of R-parameters for all volunteers following application of cream base and extract cream

\begin{tabular}{|c|c|c|c|c|c|c|c|c|c|c|}
\hline \multirow{2}{*}{ Parameter } & \multicolumn{2}{|c|}{0 week } & \multicolumn{2}{|c|}{$1^{\text {st }}$ week } & \multicolumn{2}{|c|}{$2^{\text {nd }}$ week } & \multicolumn{2}{|c|}{$3^{\text {rd }}$ week } & \multicolumn{2}{|c|}{$4^{\text {th }}$ week } \\
\hline & B & $F$ & B & $F$ & B & $F$ & B & $F$ & B & $F$ \\
\hline RO & $\begin{array}{c}0.188 \\
\pm \\
0.008\end{array}$ & $\begin{array}{c}0.202 \\
\pm \\
0.013\end{array}$ & $\begin{array}{c}0.180 \\
\pm \\
0.008\end{array}$ & $\begin{array}{c}0.197 \\
\pm \\
0.013\end{array}$ & $\begin{array}{c}0.199 \\
\pm \\
0.013\end{array}$ & $\begin{array}{c}0.200 \\
\pm \\
0.011\end{array}$ & $\begin{array}{c}0.195 \\
\pm \\
0.012\end{array}$ & $\begin{array}{c}0.209 \\
\pm \\
0.012\end{array}$ & $\begin{array}{c}0.183 \\
\pm \\
0.011\end{array}$ & $\begin{array}{c}0.204 \\
\pm \\
0.009\end{array}$ \\
\hline R1 & $\begin{array}{c}0.087 \\
\pm \\
0.011\end{array}$ & $\begin{array}{c}0.102 \\
\pm \\
0.009\end{array}$ & $\begin{array}{c}0.100 \\
\pm \\
0.006\end{array}$ & $\begin{array}{c}0.085 \\
\pm \\
0.008\end{array}$ & $\begin{array}{c}0.091 \\
\pm \\
0.009\end{array}$ & $\begin{array}{c}0.083 \\
\pm \\
0.007\end{array}$ & $\begin{array}{c}0.100 \\
\pm \\
0.007\end{array}$ & $\begin{array}{c}0.089 \\
\pm \\
0.005\end{array}$ & $\begin{array}{c}0.086 \\
\pm \\
0.009\end{array}$ & $\begin{array}{c}0.089 \\
\pm \\
0.006\end{array}$ \\
\hline R2 & $\begin{array}{c}0.534 \\
\pm \\
0.057\end{array}$ & $\begin{array}{c}0.500 \\
\pm \\
0.026\end{array}$ & $\begin{array}{c}0.443 \\
\pm \\
0.023\end{array}$ & $\begin{array}{c}0.573 \\
\pm \\
0.027\end{array}$ & $\begin{array}{c}0.534 \\
\pm \\
0.043\end{array}$ & $\begin{array}{c}0.578 \\
\pm \\
0.040\end{array}$ & $\begin{array}{c}0.483 \\
\pm \\
0.023\end{array}$ & $\begin{array}{c}0.567 \\
\pm \\
0.022\end{array}$ & $\begin{array}{c}0.522 \\
\pm \\
0.053\end{array}$ & $\begin{array}{c}0.564 \\
\pm \\
0.025\end{array}$ \\
\hline R3 & $\begin{array}{c}0.203 \\
\pm \\
0.007\end{array}$ & $\begin{array}{c}0.218 \\
\pm \\
0.013\end{array}$ & $\begin{array}{c}0.195 \\
\pm \\
0.009\end{array}$ & $\begin{array}{c}0.213 \\
\pm \\
0.012\end{array}$ & $\begin{array}{c}0.213 \\
\pm \\
0.013\end{array}$ & $\begin{array}{c}0.215 \\
\pm \\
0.012\end{array}$ & $\begin{array}{c}0.212 \\
\pm \\
0.012\end{array}$ & $\begin{array}{c}0.224 \\
\pm \\
0.012\end{array}$ & $\begin{array}{c}0.198 \\
\pm \\
0.010\end{array}$ & $\begin{array}{c}0.217 \\
\pm \\
0.011\end{array}$ \\
\hline R4 & $\begin{array}{c}0.108 \\
\pm \\
0.011\end{array}$ & $\begin{array}{c}0.118 \\
\pm \\
0.010\end{array}$ & $\begin{array}{c}0.197 \\
\pm \\
0.081\end{array}$ & $\begin{array}{c}0.099 \\
\pm \\
0.012\end{array}$ & $\begin{array}{c}0.117 \\
\pm \\
0.012\end{array}$ & $\begin{array}{c}0.103 \\
\pm \\
0.007\end{array}$ & $\begin{array}{c}0.117 \\
\pm \\
0.008\end{array}$ & $\begin{array}{c}0.115 \\
\pm \\
0.007\end{array}$ & $\begin{array}{c}0.103 \\
\pm \\
0.007\end{array}$ & $\begin{array}{c}0.101 \\
\pm \\
0.007\end{array}$ \\
\hline R5 & $\begin{array}{c}0.395 \\
\pm \\
0.048\end{array}$ & $\begin{array}{c}0.376 \\
\pm \\
0.044\end{array}$ & $\begin{array}{c}0.345 \\
\pm \\
0.032\end{array}$ & $\begin{array}{c}0.432 \\
\pm \\
0.041\end{array}$ & $\begin{array}{c}0.416 \\
\pm \\
0.036\end{array}$ & $\begin{array}{c}0.437 \\
\pm \\
0.033\end{array}$ & $\begin{array}{c}0.364 \\
\pm \\
0.024\end{array}$ & $\begin{array}{c}0.366 \\
\pm \\
0.027\end{array}$ & $\begin{array}{c}0.390 \\
\pm \\
0.023\end{array}$ & $\begin{array}{c}0.399 \\
\pm \\
0.020\end{array}$ \\
\hline R6 & $\begin{array}{c}0.805 \\
\pm \\
0.093\end{array}$ & $\begin{array}{c}0.721 \\
\pm \\
0.059\end{array}$ & $\begin{array}{c}0.892 \\
\pm \\
0.081\end{array}$ & $\begin{array}{c}0.739 \\
\pm \\
0.068\end{array}$ & $\begin{array}{c}0.783 \\
\pm \\
0.090\end{array}$ & $\begin{array}{c}0.777 \\
\pm \\
0.084\end{array}$ & $\begin{array}{c}0.737 \\
\pm \\
0.090\end{array}$ & $\begin{array}{c}0.611 \\
\pm \\
0.046\end{array}$ & $\begin{array}{c}0.779 \\
\pm \\
0.082\end{array}$ & $\begin{array}{c}0.736 \\
\pm \\
0.052\end{array}$ \\
\hline R7 & $\begin{array}{c}0.221 \\
\pm \\
0.026\end{array}$ & $\begin{array}{c}0.220 \\
\pm \\
0.026\end{array}$ & $\begin{array}{c}0.182 \\
\pm \\
0.013\end{array}$ & $\begin{array}{c}0.220 \\
\pm \\
0.026\end{array}$ & $\begin{array}{c}0.236 \\
\pm \\
0.021\end{array}$ & $\begin{array}{c}0.250 \\
\pm \\
0.020\end{array}$ & $\begin{array}{c}0.211 \\
\pm \\
0.011\end{array}$ & $\begin{array}{c}0.226 \\
\pm \\
0.014\end{array}$ & $\begin{array}{c}0.223 \\
\pm \\
0.016\end{array}$ & $\begin{array}{c}0.231 \\
\pm \\
0.011\end{array}$ \\
\hline R8 & $\begin{array}{c}0.101 \\
\pm \\
0.012\end{array}$ & $\begin{array}{c}0.100 \\
\pm \\
0.007\end{array}$ & $\begin{array}{c}0.080 \\
\pm \\
0.006\end{array}$ & $\begin{array}{c}0.113 \\
\pm \\
0.008\end{array}$ & $\begin{array}{c}0.109 \\
\pm \\
0.014\end{array}$ & $\begin{array}{c}0.118 \\
\pm \\
0.013\end{array}$ & $\begin{array}{c}0.095 \\
\pm \\
0.008\end{array}$ & $\begin{array}{c}0.120 \\
\pm \\
0.010\end{array}$ & $\begin{array}{c}0.097 \\
\pm \\
0.012\end{array}$ & $\begin{array}{c}0.115 \\
\pm \\
0.008\end{array}$ \\
\hline R9 & $\begin{array}{c}0.015 \\
\pm \\
0.002\end{array}$ & $\begin{array}{c}0.016 \\
\pm \\
0.001\end{array}$ & $\begin{array}{c}0.015 \\
\pm \\
0.001\end{array}$ & $\begin{array}{c}0.015 \\
\pm \\
0.002\end{array}$ & $\begin{array}{c}0.014 \\
\pm \\
0.002\end{array}$ & $\begin{array}{c}0.015 \\
\pm \\
0.002\end{array}$ & $\begin{array}{c}0.017 \\
\pm \\
0.001\end{array}$ & $\begin{array}{c}0.014 \\
\pm \\
0.002\end{array}$ & $\begin{array}{c}0.015 \\
\pm \\
0.002\end{array}$ & $\begin{array}{c}0.013 \\
\pm \\
0.002\end{array}$ \\
\hline
\end{tabular}

Note: $B=$ cream base; $F=$ extract cream 
study period after the application of the base, but this increase was tremendous in the $1^{\text {st }}$ and $3^{\text {rd }}$ week of study. On the other hand, application of the extract cream resulted in a decrease in $\mathrm{R} 9$ values except in the $1^{\text {st }}$ week when values increased.

\section{DISCUSSION}

\section{R0-parameter}

R0 is the first maximum amplitude or the highest point of the first curve, i.e., Uf. It is known as final distension or skin dispensability [2]. This has an implication for the firmness of skin. It represents passive behavior of the skin to force. Changes in R0 values produced by the cream base as well as the extract cream were significant during a period of 4 week study. In this regard, there was no significant between the cream base and extract cream throughout the study period.

Epidermal hydration influences skin mechanical parameters such as Uf, and significant increase in Uf is mainly due to increase in Uv [3]. The significant increase in Uf after application of the extract cream may be attributed to the moisturizing proerty of the fenugreek seed extract. Fenugreek seeds are primarily composed of galactomannans whose high water contents make them naturally hydrating, which promores glowing skin [7].

\section{R1-parameter}

This parameter is the first minimum amplitude or the lowest point of the first curve. It represents the ability of the skin to return to its original state. Changes in $\mathrm{R} 1$ values produced by the base and the extract cream were significant with respect to time. This was particularly so for the extract cream in the $1^{\text {st }}$ and $2^{\text {nd }}$ week. There was significant difference in $\mathrm{R} 1$ values between the base and the extract cream only in the $1^{\text {st }}$ week of study.

The significant decrease in $R 1$ values of the extract cream indicate improvement in the ability of the skin to revert back to its original state after application of stress as the mathematical relationship, $\mathrm{R} 1=\mathrm{Uf}-\mathrm{Ua}$, shows. From the results both $\mathrm{Ua}$ and Uf increased significantly but the increase in $\mathrm{Ua}$ was more than that of Uf in the case of the extract cream. Thus, this led to a significant decrease in $\mathrm{R} 1$ values, which in turn improved skin elasticity following application of extract cream.

\section{R2-parameter}

This is a measure of the gross elasticity of the skin, including viscous deformation, and is represented by the ratio of "the ability of redeformation of skin" to "final distension", i.e., Ua/Uf[2]. The closer the value is to 1 (i.e., $100 \%$ ), the more elastic the skin is. The changes in $\mathrm{R} 2$ values produced by both the cream base and the extract cream were significant with respect to time. However the change in $R 2$ values was only significant after the $1^{\text {st }}$ week in the case of the base and in the $1^{\text {st }}$ and $2^{\text {nd }}$ week in the case of the extract cream. R2 is one of the main parameters for assessing skin elasticity and ageing [2]. Both $\mathrm{Ua}$ and Uf increased significantly but the increase in Ua was more pronounced and linear than Uf in the case of the extract cream. This is why the extract cream produced greater improvement in skin elasticity.

\section{R3-parameter}

This parameter is indicated by the last maximum amplitude or the highest point of the last curve, and is a measure of maximal skin deformation after the last suction [3]. Tiring effects of the skin are visible, as the amplitude increases with each new suction, when compared to the maximum amplitude of 
the previous curves. Although changes in R3 values by both creams were significant over the 4-week period,there was no significant difference between the two creams in respect of this parameter.

\section{R4-parameter}

This is measured by the last minimum amplitude or the last measuring point, is an indication of residual skin deformation after release of the last suction [3]. Compared to the minimum amplitude of the first curve, tiring effects of the skin are visible, as the ability of redeformation decreases with each new suction. Changes in R4 values produced by the base were insignificant with respect to time, unlike those produced by the extract cream. Thus, the effects of the two creams were significantly different in relation to this parameter.

\section{R5-parameter}

This parameter is the so-called net elasticity of skin without viscous deformation [2]. Elastic recovery is represented by the ratio of "immediate retraction" to "immediate distension", i.e., Ur/Ue [3]. The closer the value is to 1 (i.e., $100 \%$ ), the more elastic the skin is. Changes in R5 values produced by both creams were significant and the changes were significantly different between the two creams only in the 1 st week.

Cutaneous changes arising from photoaging are due to degeneration of elastic fibres in the dermis [9]. The more pronounced increase in skin elasticity following the application of the extract cream may be attributed to the antioxidants present in Fenugreek seeds extract [10] which in turn to can be linked to its content of flavonoids, flavones and polyphenols [11]. According to free radical theory, ageing is caused by the slow cumulative oxidation of body tissues over a lifetime [12]. Antioxidants intervene at different levels of oxidative processes, e.g., by scavenging free radicals and lipid peroxyl radicals, by binding metal ions or by removing oxidatively damaged biomolecules [13].

\section{R6-parameter}

This parameter is the portion of viscoelasticity on the elastic segment of the curve. It indicates the relative contributions of viscoelastic, viscous and elastic deformation to total deformation [14]. It is represented by the ratio of "visco-elastic" to "elastic distension", i.e., Uv/Ue. The smaller the value, the higher the elasticity is. Variation in R6 values produced by the two creams wa significant only in the $1^{\text {st }}$ week of study. The increase in viscoelasticity may be due to hydrating effect of the creams. The increase in Uv and Uv/Ue indicates a decrease in the viscosity of the interstitial fluid as a result of increased water content and changes in the proteoglycan composition and/or structure. The accumulation of water in the dermis diminishes friction between the fibers and facilitates the movement of the interstitial fluid [3].

\section{R7-parameter}

$\mathrm{R} 7$ is referred to as biological elasticity. This parameter relates elasticity with final distension. It is represented by the ratio of "immediate retraction" to "final distension", i.e., Ur/Uf. The closer the value is to 1 (i.e., $100 \%$ ), the more elastic the skin is. R7 values produced by by both creams varied with the duration of their application. Cutaneous elasticity is described by two parameters, namely, viscoelastic ratio and biological elasticity $[3,15]$. The improvement in biological elasticity and hence, cutaneous elasticity, induced by both creams may be linked to their oily nature. The paraffin oil used, which is a mixture of hydrocarbons, constituted the outer phase of the cream and thus formed a layer over the surface of the skin and protected it from photoaging which is caused by certain biochemical changes within the skin induced by sunlight. Galactomannans may or may not have played a role since they constitute an 
extracellular deposition of the endosperm of fenugreek seeds and serve as energy reserves during germination. An effective amount of a cosmetic or dermatological composition comprising galactomannans is said to be used for preventing or treating skin aging $[16,17]$.

\section{R8-parameter}

This parameter is equal to Ua (i.e., total recovery) of the first curve. It is the viscopart i.e. the area under the suction part of the deformation curve [2]. The closer Ua and Uf are, the greater is the ability of the skin to return into its original state. Change in $\mathrm{R} 8$ values became significant in the $1^{\text {st }}$ week in case of the cream base while significant variation in $R 8$ values between the cream base and fextract cream was observed only in the $1^{\text {st }}$ and $3^{\text {rd }}$ week of study. The greater increase in total recovery of the skin after application of the extract cream may be attributed to the combined effect of the moisturizing action of the extract and the ability of its antioxidant components to protect the skin from photoaging $[7,13]$.

\section{R9-parameter}

This parameter represents the tiring effects of the skin after repeated sucking in the skin. It is the difference between the last and the first maximal skin deformation, i.e., R3 - R0. The smaller the value of $\mathrm{R} 9$, the smaller the tiring effects are. Significant changes in R9 values with time were produced by the cream but change in the values for extract cream were insignificant.

\section{CONCLUSION}

Both the cream base and the cream formulation containing the extract of Fenugreek seeds produced significant improvements in all skin parameters related to elasticity, age, hydration and fatigue but the extract cream demonstrated more pronounced effects in some cases.

\section{REFERENCES}

1. Lawrence HB, Gray's Anatomy, Integumental System, $38^{\text {th }}$ ed., Churchill Livingstone 1995; 376-417.

2. Sungyeon $A$, Seunghun $K$, Haekwang L, Seogjoon $M$, Ihseop $C$. Correlation between a cutometer and quantitative evaluation using Moire topography in age-related skin elasticity. Skin Res. Techn. 2007; 13: 280-284.

3. Hristo $D$. Use of cutometer to assess epidermal hydration. Skin Res. Techn. 2000; 6: 239-244.

4. Schlangen LJM, Brokked D, Kemenade PMV. Correlation between small aperture skin suction parameters: Statistical Analysis and Mechanical Model. Skin Res. Techn. 2003; 9: 122-130.

5. Alfred M.; Pilar B.; Chun AHC. Physical Pharmacy, Physicochemical Principles in Pharmaceutical Science. $4^{\text {th }}$ edn, New York: Waverly International Maryland; 1993. 486 p.

6. Herbert AL.; Martin MR.; Gilbert SB. Pharmaceutical Emulsions, Pharmaceutical Dosage Forms: Disperse Systems. Vol.1, New York: Marcel Dekker; , 1988. $117 p$.

7. Aburjai T, Natsheh FM. Plants used in cosmetics. Phytother. 2003;17: 987-1000.

8. International ethical guidelines for biomedical research involving human subjects. Prepared by the Council for International Organizations of Medical Sciences (CIOMS) in collaboration with the World Health Organization (WHO) Ort/Förlag: Geneva : CIOMS

9. Hay RJ. Skin Disease. British Medical Bulletin 1993; 49: 440-453.

10. Kaviarasan $S$, Naik $G H$, Gangabhagirathi, $R$. Anuradha CV, Priyadarsini KI. In vitro studies on aniradical and antioxidant activities of fenugreek (Trigonella foenum graecum) Seeds. Food Chemistry 2007; 103: 31-37.

11. Jung $K$, Richter J, Kabrodt $K$, Lucke IM, Schellenberg I, Herrling TH. The antioxidative power (AP). A new quantitative time dependent (2D) Parameter for the determination of the antioxidant capacity and reactivity of different plant. Spectrochimica Acta, Part A 2006; 63: 846-850.

12. Takema $Y$, Yorimoto $Y$, Kawai M., Imokawa G. Age-related changes in the elastic properties and thickness of human facial skin. British J. Dermatology 1995; 131: 641-648.

13. Dreher F, Maibach H. Protective effects of topical antioxidant in humans. Oxidants and Antioxidants in Cutanous Biology 2001; 29: 157-164.

14. Ames KR, Albert TC. Quantification of skin elasticity changes associated with pulsed carbon dioxide. Laser Skin Resurfacing, Arch Facial Plastic Surg 1999; 1: 272-275.

15. Hong SY, Sei HB, Chil HO. Quantitative measurements of desquamation and skin 
Akhtaret al

elasticity in diabetic patients. Skin Res. Techn. 2002; 8: 250-254.

16. Henriette K. Paraffinum Liquidum B.P. The British

Pharmaceutical Codex, Churchill Livingstone, Edinburgh, UK, 1995; p 1911.
17. Lucas C, Poirier F, Laperdrix C. Use of galactomannons as an active cosmetic agent. US Patent: 20060182824, 2006. 